\title{
Twitter y poesía no creativa por Karen Villeda y Denise Audirac en su obra POETuitéame
}

\author{
Twitter and Uncreative Poetry \\ by Karen Villeda and Denise Audirac \\ in her Work POETuitéame
}

\author{
Daniel Escandell Montiel \\ Manchester Metropolitan University \\ d.escandell.montiel@mmu.ac.uk
}

RESUMEN: El presente artículo estudia la obra de poesía digital POETuitéame de las autoras mexicanas Karen Villeda y Denise Audirac desde las teorías del arte conceptual y la escritura no creativa desarrolladas por Kenneth Goldsmith y la apropiación y resemantización semionáutica de Nicolas Bourriaud. Para ello, en primer lugar, se establece una panorámica desde el punto de vista principal de la recepción de la poesía digital, culminando en la eclosión de la tuitpoesía como muestra de las escrituras de la red social de tipo poético. Esta base tuitpoética es esencial para la ejecución final de la obra de Villeda y Audirac. En segundo lugar, se abordan las teorías de Goldsmith y Bourriaud como eje principal para, finalmente, proceder con la aproximación al estudio final de la obra y sus implicaciones no creativas y semionáuticas como ejecución conceptual de una escritura 2.0.
PALABRAS ClAVE:

Escritura no creativa; semionauta; red social;

Twitter; ciberpoesía; poetuitéame.
KEYWORDS:

Uncreative writing;

Semionaut;

Social Network;

Twitter;

Cyberpoetry

Poetuitéame.
ABSTRACT: This article studies the digital poetry work POETuitéame by Mexican authors Karen Villeda and Denise Audirac using the theories of conceptual art and non-creative writings of Kenneth Goldsmith, as well as the concepts of appropriation and the semionautic re-semantization of Nicolas Bourriaud. To do this, the article first establishes the panorama of digital poetry from the point of view of its reception, culminating in the emergence of tweet-poetry as a sample of the poetic writings in social networks. This tweetpoetry foundation is essential for the final execution 
of Villeda and Audirac's work. Secondly, the theories of Goldsmith and Bourriaud are addressed as a main axis to finally address the study of the work POETuitéame and its non-creative and semionautic implications as a conceptual execution of 2.0 writing.

recepción: 01 septiembre 2018

aceptación: 08 enero 2019

\section{Introducción: la trayectoria poética de Karen Villeda}

En estas páginas centramos nuestra atención en Karen Villeda y en su proyecto POETuitéame (2014), en colaboración con Denise Audirac, una obra literaria que opera sobre la red social Twitter para retomar textos de terceros, usando para ello parámetros de escritura no-creativa, en la medida en que emplea tuits ya existentes que son recombinados, tal y como veremos por extenso en posteriores apartados. Villeda es una autora mexicana nacida en Tlaxcala en 1985 cuya obra ha sido descrita por diversos investigadores como altamente original e innovadora (Cross 2012: 90-92) y ha sido recogida en el tercer volumen de la Electronic Literature Collection que publica y aloja el MIT, un honor que comparten todavía pocos autores en lengua española.

La propia Villeda tiene una página web personal Ilamada POETronic ${ }^{1}$ que, desde su propio título, es toda una declaración de intenciones. En ella encontramos destacada la sección "Poesía + Multimedia", donde recoge un total de nueve obras (la última en proceso) en forma de videopoemas, historias interactivas, poesía visual, stop-motion y poesía hipertextual. En este contexto, vemos cómo su experimentación con lo transmedia, multimedia y electrónico ha convivido con la publicación de poemarios de corte más tradicional, en cuanto a que éstos son impresos.

Por tanto, POETronicA es un proyecto web que aglutina las creaciones poéticas de Villeda que trascienden el papel y, dentro de éste, POETuitéame es un punto de inflexión que abre definitivamente el camino a una escritura poética nativamente electrónica por parte de la autora, frente a los textos precedentes, inspirados, basados o derivados de los poemarios

1 Disponible en: <http://www.poetronica.net>. 
de corte más tradicional (esto es, impreso), de la autora de Tlaxcala. Si Villeda es descrita en perfiles como el de la Enciclopedia de la literatura en México como "poeta y net-artist" (2011), es evidente que POETuitéame ha sido una pieza fundamental para potenciar su peso internacional como artista digital.

En consecuencia, resulta evidente, como han señalado previamente otros investigadores (Remírez 2017), que la obra de Villeda no se circunscribe a una experimentación digital aislada, sino que esta voluntad experimentadora de su escritura ha tenido también su reflejo en la utilización de este espacio virtual y sus recursos tecnológicos para hacer una exploración de campo que trasciende, como veremos, lo anecdótico.

Sin embargo, podemos afirmar que, dentro del panorama de la escritura digital de Villeda, esta pieza que nos ocupa es quizá la que tiene mayor complejidad técnica y eso explica la colaboración con la también mexicana Denise Audirac, quien corresponde a un perfil mucho más tecnológico e informático con un interés profesional que se ha centrado en la interacción humano-máquina.

Si prestamos atención a la obra poética de Villeda nos encontramos con cuatro poemarios: Tesauro (2010), Babia (2011), Dodo (2013) y Constantinopla (2013), todos ellos elogiados por la crítica. El proyecto POETuitéame no se materializa hasta 2014 dentro de una trayectoria de experimentación digital que, sin embargo, ha sido paralela a la de publicación tradicional.

En el mismo año de publicación de Tesauro, Villeda crea una serie de poemas con el mismo nombre que apuestan por la naturaleza digital y que nacen a raíz del poemario impreso. Si bien algunos textos son compartidos, el Tesauro digital es deudor del analógico y es la expresión de la voluntad experimentadora cultivada en un laboratorio de ciberpoesía a partir de los versos originales. En 2013 se inicia Dodo, donde se apuesta por stop-motion y que, como sugiere su nombre, está igualmente basado en un poemario analógico de la autora. Es en 2014 cuando encontramos su primera obra nativamente multimedial con Paisaje aéreo de la Tierra, paisaje terrestre de la Luna con material audiovisual obtenido mediante la grabación de bacterias. Estos son los antecedentes para POETuitéame dentro de la propia trayectoria de la autora y se evidencia de este modo que su voluntad experimentadora estaba ya en su propia escritura analó- 
gica y la búsqueda de nodos de conexión con su traslación a lo digital y multimedia.

Esta obra no supone, con todo, un cambio radical en la trayectoria de Villeda: no sólo se inscribe, con lógica y coherencia, en su trayectoria poética, sino que además no ha supuesto una renuncia a los medios tradicionales. La autora, que también ha ejercido como ensayista, ha publicado los libros Tres (2016) y Visegrado: microensayos literarios de Hungría, Polonia y República Checa (2018) dentro de esta línea de trabajo, así como literatura infantil y juvenil con Cuadrado de Cabeza: el mejor detective o eso cree él (2015) y Pelambres (2016).

Esto sugiere que, si bien la línea poética sí ha apostado cada vez más por una confluencia de elementos experimentales, exploratorios y técni$\cos$, la autora ha mantenido una firme trayectoria vinculada al libro tradicional en los otros ámbitos de su creación. Y, tal y como había sucedido con su poesía, estas creaciones han sido igualmente reconocidas con premios (de hecho, tanto su cuento de 2015 como su ensayo de 2018 se publican como ganadores de los Premios Bellas Artes en sus respectivas modalidades los años anteriores).

Este es un juego de equilibrios que hemos visto en múltiples autores, pero en las siguientes páginas nos centraremos en POETuitéame como obra fundamental para comprender la experimentación que propone $\mathrm{Vi}$ lleda, y que se ejecuta en este caso en colaboración directa con Denise Audirac; cómo se inserta en la trayectoria general de la poesía digital y, cómo no, dentro de la expansión creativa de la poeta. A tales efectos, en los siguientes apartados trazaremos una exploración general de la poesía electrónica internacional (si bien habrá un especial énfasis en la esfera hispanohablante), para luego dar paso al papel que asume el receptor (lector, pero también lectoespectador y, en este caso, lectoautor o lectorusuario); las teorías fundamentales que sustentan la experimentación de POETuitéame (esto es, la escritura no-creativa y la semionáutica) y, por último, el análisis de la obra junto con una exposición de la experiencia receptora y de uso. 


\section{Aproximación general a la ciberpoesía: marco creativo de la poesía electrónica internacional}

Tras haber trazado una panorámica sobre la producción literaria de Karen Villeda, consideramos conveniente ofrecer al lector una aproximación de carácter general a la poesía electrónica, o poesía digital o ciberpoesía - según la línea de trabajo que sigamos desde un punto de vista de las taxonomías de la academia-. De este modo, es posible situar mejor la propia acción creativa de Villeda dentro del panorama internacional de la experimentación digital, que dentro del campo poético sigue siendo "no sólo asunto menor en términos cuantitativos, es también, en términos críticos, rara y marginalmente analizada" (Baetens 2008: 243), pese a que es un campo que se presta fácilmente a la experimentación y exploración de las fronteras del lenguaje y la literatura en el ámbito digital, más allá de la edición electrónica de los émulos impresos: "inmersos en plena sociedad del conocimiento, una vez superada la sociedad de la información, la poesía no es ajena a ese cambio que ha supuesto el uso de las nuevas tecnologías a la hora de relacionarnos" (Montoto 2011: 41).

El carácter experimental otorga a esta escritura una enorme relevancia y ha sido foco de atención de estudios previos desde múltiples perspectivas, incluyendo los modos de interacción y su influencia en la recepción como eje fundamental de la logoemesis (Escandell 2017: 68). Sin embargo, podemos afirmar que quizá no se ha desarrollado tanto el análisis desde el punto de vista de la escritura digital y la creación en línea, o éste ha estado quizá más fragmentado debido a la complejidad formal de muchas de las propuestas que suelen situarse en el paraguas de las etiquetas antes mencionadas.

Los resultados de la escritura poética de tipo digital han ido desde el juego electrónico (con adaptaciones directas, incluso de programas informáticos y videojuegos a creaciones de tintes poéticos) hasta la ilegibilidad absoluta, pasando por una revitalización de la poesía performativa, actoral, denominada también perfopoesía, como vamos a ver en esta panorámica de los fenómenos entorno a la poesía digital que conducen finalmente hacia el proyecto POETuitéame planteado por Karen Villeda y Denise Audirac. 
A la hora de plantear una definición global que permita abarcar toda la fenomenología que vamos a trazar, podemos decir que la poesía electrónica es la que ha sido creada expresamente para ser leída en pantalla, por lo que ya no se trata de dominar el espacio en blanco de la hoja, bidimensional, sino el espacio virtual del monitor, multidimensional, aun cuando esta poiesis pueda nacer de la adaptación de poemas creados tradicionalmente. Siempre teniendo en cuenta que estos planteamientos surgen de asumir una respuesta determinada a la pregunta "¿es la poesía en esencia algo escrito en un papel? ¿Habla su definición per se de tinta negra sobre página? A lo sumo será texto, texto que aletea en un mundo fluctuante, multiforme, en transformación " (Castaño 2011: 22).

Se entiende, por lo general, que hay tres rasgos a considerar: la interacción que convierte al lector en autor, la concepción multimedia (visual, sonora), y la fuerza sincrónica derivada de su estado de mutación constante al someterse a la interacción, hasta tal punto que un texto generado puede ser irrecuperable por la imposibilidad de reproducir exactamente las mismas circunstancias que lo constituyeron.

En un contexto hipermedia como el que se genera en estas formas de expresión poética existe "un lenguaje específico, que desarrollando los códigos propios de cada una de las expresiones artísticas que hibrida, sea capaz de ofrecer algo más que la simple suma de las mismas sobre una base literaria" (Martín 2011: 29), lo que implica necesariamente que el autor, el poeta, debe concebirse en este entorno como un "poeta multimedia [que] debe conocer, comprender y adentrarse en las diferentes disciplinas" (29) que componen el espectro creativo de la ciberpoesía y de las nuevas formas poéticas. ${ }^{2}$

2 Debemos tener en consideración, sin embargo, que el origen de estas formas poéticas, como en tantas otras veces, no es ni mucho menos tan absolutamente coetáneo como podría percibirse por su aparición en formatos hipermedia. En este sentido, C. T. Funkhouser ha desarrollado por extenso el análisis del origen de las formas poéticas digitales en su libro Prehistoric Digital Poetry. An Archaeology of Forms, 19591995, publicado en 2007. Ahí, se presta atención especialmente al origen de formas poéticas digitales como la generación automatizada en diferentes grados de textos y a los poemas cinéticos. Un tercer pilar de su libro es el rastreo de los precedentes de lo hipermedia. 
Asimismo, y como rasgo que será de gran importancia para el análisis de la propuesta de Villeda y Audirac, los textos poéticos que veremos resultan verticales en su concepción: el autor poético (solo o en equipo para dar respuesta a la propuesta tecnológica de la creación diseñada) ofrece la obra al lectoespectador (Mora 2012), que es receptor, pero no interviene necesaria o explícitamente en la tarea escritural. Frente a esto, como veremos, Villeda y Audirac se posicionan como facilitadoras del acto poético a través de su herramienta para la intervención autoral de los receptores.

\section{Lectoespectadores y cocreadores: el receptor y su papel ante la poesía digital}

De nula o muy limitada interacción para el receptor lectoespectador resulta la poesía visual digital quizá más tradicional, aquella que se concibe en su aspecto fundamental como la heredera de la poesía visual o los primeros experimentos audiovisuales de la vanguardia. Se trata, en definitiva, de un formato creativo que está mucho más cerca de la creación audiovisual de esa tradición que de la explotación de los componentes informáticos y de las Tecnologías de la Información y la Comunicación (TIC).

Por ejemplo, Ana María Uribe crea entre 1997 y 2003 la colección Tipoemas y Anipoemas, imágenes en movimiento (formato GIF, ${ }^{3}$ principalmente) o estáticas, en las que se juega con caracteres para realizar poesía visual. En el caso de Uribe, los tipoemas son estáticos y tradicionales por completo, pero frente a ellos están los anipoemas (poemas animados). A los originales, en GIF, y por tanto bucles limitados y sin sonido, se añaden creaciones posteriores sobre tecnología Flash, ${ }^{4}$ mucho más elabora-

3 Formato gráfico usado para imágenes estáticas y, sobre todo, en movimiento. El formato fue creado por CompuServe en 1987 para dotar de un formato de imagen a color sus áreas de descarga de ficheros, con un límite de 256 colores (lo que afecta a su calidad de imagen).

4 Programa informático creado por Macromedia, compañía absorbida en 2005 por Adobe, destinado a la creación de audiovisuales interactivos para internet, por lo que se emplea tanto para la reproducción de vídeos (como YouTube, DailyMotion, y otros muchos), o para la creación de hipermedias, lo que va desde presentaciones interactivas para sitios web como videojuegos en sentido estricto. Las producciones hechas sobre este programa (en formatos informáticos SWF o FLV, principalmente) se denominan igualmente Flash o animaciones Flash. Con el auge del HTML5, así como por la integración 
dos que aprovechan más intensamente las posibilidades digitales. Pese a todo, debemos tener en cuenta que incluso las creaciones más complejas serían realizables en otros formatos de cine o animación, pues el receptor es puramente pasivo, y por tanto están en línea con las aproximaciones de la poesía visual al cine en pleno apogeo vanguardista.

Si bien el archivo no es estrictamente de vídeo, estamos al fin y al cabo ante videopoemas formados por tipografías en movimiento Así pues, corren el peligro de ser, tan sólo, "videoarte con pinceladas poéticas, no una iniciativa donde la fuerza del texto, la calidad de este se ve reforzada por una sinergia de disciplinas artísticas" (Martín 2011: 34). La novedad llega, en estos casos, más por la capacidad de proyección de la obra artística, y la posibilidad de que sea el autor poético el responsable único de todas las tareas técnicas, si así lo desea (las comunicaciones también facilitan en la misma medida el trabajo colectivo). El videoarte ha tenido entre sus creadoras más populares de la Web 2.0 a la española Ajo con sus publicaciones en forma de micropoemas con soporte audiovisual en YouTube (Aguilar 2014).

Desde luego, la interacción con el receptor artístico, así como la aplicación de elementos multimedia no son exclusivas de la concepción digital de la poesía, con antecedentes tan obvios como el collage, o la poesía visual. Por ejemplo, aunque creada en formato digital sobre tecnología Flash combinando imagen, sonido (los versos en árabe de la presentación, y la música ambiental) y texto (los versos en inglés, tanto de la presentación, como los de los poemas que componen la obra misma), la creación Like Stars in a Clear Night Sky (2006), de Sharif Ezzat, no presenta elementos de lectoautoría directa: el lector puede pulsar sobre las estrellas azules que van llenando el cielo nocturno para escoger qué historias, qué versos, recibir, pero no tiene opción real de crearlos o modificarlos.

Por otro lado, y como muestra del potencial de interacción del lector, los primeros experimentos con el uso de algoritmos generativos para componer textos aleatorios todavía manifiestan cierta capacidad de sorprender a los neófitos. Esto se ha sumado en la actualidad a diversas interfaces

de formatos de vídeo en el estándar, el sistema Flash está retrocediendo en presencia en línea. A finales de 2011 Adobe anunció que dejaba de lado el desarrollo de este software para plataformas móviles, como Android. 
gráficas, ${ }^{5}$ lo que se ha usado hasta la saciedad en exposiciones o páginas web. Un ejemplo de estas tendencias de poesía generada por el ordenador es Bacterias argentinas: de las redes tróficas a las redes del lenguaje de Santiago Ortiz. Esta creación ha existido también como elemento expuesto artísticamente en la muestra Juego Doble: dos ecosistemas, con la creación de Ortiz junto a In Silico, de Florence Gouvrit, en la Embajada de España en México en el año 2005. Se titulaba entonces Palabra de Bacteria y era descrita como una suerte de emulación de un ecosistema en el que los organismos se fagocitan entre ellos según su información genética, que viene dada por los textos de una narración fragmentada; al devorarse entre sí las bacterias absorben su información textual-genética y la incorporan a su propia narrativa, creando organismos cada vez más grandes y dominantes con mayores capacidades de absorción.

El sistema funciona de manera autónoma una vez que lo hemos iniciado, aunque al mismo tiempo el lector se convierte en un ente activo creador al interactuar, seleccionando bacterias para poder oír su mensaje, gracias a la voz grabada de Edgardo Manzetti. Aunque podemos discutir la barrera entre lo narrativo y lo poético, aquí la integración tecnológica ha penetrado en todos los campos del arte y no se puede esperar otra cosa de la poesía.

Hay, eso sí, una categoría intermedia, la de la poesía asistida, como la propuesta homónima PAC - Poesía Asistida por Computadora de Eugenio Tisselli en 2006, quien nos ofrece una "musa cibernética". Para probar el sistema desarrollado por Tisselli, introducimos el verso "contemplar las palabras" de José Agustín Goytisolo, lo que nos descompone el verso en palabras, teniendo que escoger una, según las instrucciones ofrecidas por la plataforma. Así, nosotros escogemos, dada la recomendación, palabras. Como nos advierte la misma página web, "es posible que las nuevas palabras rompan la coherencia gramatical"; al obtener como sustituto el térmi-

5 Medio con el que el usuario se comunica con un ordenador o dispositivo electrónico, abarcando todos los puntos de contacto entre el usuario y el equipo. En un ordenador, por ejemplo, serían el teclado y el ratón, aunque también la imagen proyectada en el monitor, siendo esta la interfaz gráfica de usuario (en inglés graphic user interface, abreviado GUI). La interfaz gráfica de usuario es la general del sistema operativo del dispositivo informático, pero también la de cada una de sus aplicaciones y cómo se comunica con el usuario (sonidos, mensajes, iconos, descriptores, etcétera). 
no charla lo modificamos en plural. Finalmente, pulsamos en la intrigante opción sacudir (de la que no se nos da información): esto genera el texto "prevea lo opuesto" (sería posible seguir modificando, mediante estos sistemas, el verso hasta donde se desee). Pulsamos en finalizar, y se nos invita a enviar por correo electrónico el verso generado, que será publicado en la web. La combinatoria, con una intervención mucho más directa por parte del usuario, genera versos a raíz de un verso o texto aleatorio.

La concepción misma de estos mecanismos de poesía generada por ordenadores, con mayor o menor grado de interacción, implica un problema de calidad del que se quejan en ocasiones los lectores, polémica clásica y esperable al explorar las fronteras de las reglas artísticas establecidas. Se ha insistido en que

no es suficiente con tener nuevos tipos de signos (móviles, fuertemente visuales, interactivos) y nuevos tipos de soportes mediáticos (una pantalla de ordenador, una pantalla de proyección, un ambiente de realidad virtual). Incluso si esos dos elementos (nuevos tipos de signos, nuevos tipos de soporte) fueran necesarios, tenían que ser completados por nuevos tipos de contenido, preferentemente ligados a las características específicas de los signos y los medios (Baetens 2008: 247).

Por tanto, aunque se da una influencia creativa, ésta no debe ser considerada determinista frente a la cualidad creativa: que un software cree textos no implica que éstos, en sí mismos, tengan valor poético, pues esto debe ser juzgado por cuestiones ajenas a cómo se ha creado.

En oposición a estos experimentos de ciberpoesía generada por máquinas, hay también una serie de creaciones en las que se emplean los recursos hipertextuales desde la voluntad completa del autor o autores, como el uso del hiperenlace para crear una lectura no-lineal. Por ejemplo, en el caso de la catalana Intermínims de navegació poética, obra de Ramon Dachs, de 1996 y que desde 2004 se volvió plurilingüe en castellano, francés e inglés.

Tecnológicamente mucho más simple que los anteriores ejemplos, su ejecución es una muestra de la poesía hipertextual. Así, en este tipo de desarrollo creativo lo poémico se construye -en ocasiones, únicamente- sobre hipervínculos (internos o externos) para componer la creación poética. Estos intermínimos se dejan explorar por versos, palabras o ini- 
ciando una lectura secuencial, estableciendo una relación abierta entre las partes en la que la lectura completa deja de tener sentido para explorar la importancia de la creación de la experiencia de lectura poética por parte del visitante. El lector puede dejarse llevar, paso a paso, por el camino completo, o empezar a leer a partir de la estructura alfabética por donde quiera; desde cada poema, algunas palabras son hiperenlaces que le llevan a otro poema. Los enlaces y páginas no se generan dinámicamente, sino que están establecidos y diseñados uno a uno sobre HTML estático, y algunos caminos se cortan, limitando el alcance de lectura. ¿Ha terminado entonces la experiencia lectora, o debemos regresar al principio —o escoger libremente otro comienzo- para completar la lectura? Es una decisión que se deja abierta al lector, como lo es igualmente la posibilidad de cambiar, en cada página, entre las diferentes versiones: la original catalana, la castellana, francesa o inglesa, a través de unos botones siempre presentes.

El iPad ha abierto también el campo a sus propias exploraciones ciberpoéticas, apostando por la interacción mediante el flujo que aporta la pantalla táctil de la tableta. En este sentido destaca la obra de Jason Edward Lewis, que ha dado a conocer múltiples aplicaciones para el dispositivo de Apple que corresponden al ideal logoemético y a la logofagia con su vocación de visibilización e invisibilización textual (Escandell 2017: 69). A continuación, expondremos sólo sus primeras publicaciones, por el valor fundacional que suponen. Son experiencias lectoras que se basan en la interacción humano-máquina, de manera que al tocar la pantalla generamos el texto, ya sea en forma de versos o de palabras aisladas. Forman parte del proyecto P.o.E.M.M, Poems for Excitable [Mobile] Media.

En el caso de Speak (2010) las letras están entre las sombras, en un fondo negro que impide que se puedan ver con facilidad. Cuando interactuamos con ellas desplazando el dedo sobre la pantalla el efecto parece emular que tiramos de un hilo que se dibuja siguiendo la trayectoria que marcamos. Puede salir una palabra o una frase, entera o no, en función de la letra que hayamos enganchado. Al soltar ese hilo, se desvanece rápidamente en la negrura, por lo que la lectura es fragmentaria. Además del texto poético compuesto para la ocasión, los textos manipulados pueden provenir no sólo de los poemas escritos previamente por el autor para formar parte del corpus poético de la aplicación, sino también de la cro- 
nología de Twitter del usuario del dispositivo, ${ }^{6}$ o incluso por hashtags. ${ }^{7}$ Otra opción es que el propio usuario escriba su poema: el programa lo introducirá en su repertorio textual.

En Know (2011) se nos presenta una masa informe de las letras blancas sin perfilar, amontonadas y agolpadas en un espacio insuficiente. Pulsamos y cobran preeminencia: el morado las colorea y podemos leer esas palabras, moverlas, pues se impulsan con el empuje de sus extremos. Las demás, mientras tanto, siguen flotando en la limitada deriva de la pantaIla. Cuenta tanto con poemas escritos por Lewis como por otros escritores invitados (J. R. Carpenter, David Jhave Johnston, Loss Pequeño Glazier, Jason Camlot y Jerome Fletcher) desde su actualización a la versión 2.0 en 2012.

La filosofía del mundo 2.0, con todo su ideal rizomático y el potencial creativo de la comunidad y su colectivización, ha dado ya algunos ejemplos que consideramos relevantes en relación con la comunidad y la estructura rizomática de internet. Un hito imprescindible de esta fenomenología es la obra de creación poética colectiva Raphèl (2001), liderada por Bernardo Schiavetta. Se trata de "una obra en marcha, colectiva, y plurilingüe, que explora la relación dialéctica entre lo significativo y lo que no tiene sentido, así como el desplegarse hipertextual de un texto infinito" (Baetens 2008: 247) que se ofrece en HTML o en Flash. En este

6 En este caso, la aplicación se conecta a internet para recuperar los datos de usuario de Twitter del propietario del dispositivo, iPad o iPhone, y muestra en pantalla los últimos tuits publicados por las personas que sigue en la red social. Puede manipularlos de la misma manera que los versos de los poemas. Esta función no estaba presente en la aplicación original, publicada el 3 de diciembre de 2010, sino que se introdujo en revisiones posteriores.

7 Del inglés hash y tag (almohadilla y etiqueta), por su forma (\#ejemplo). Se registra habitualmente su uso como masculino. En castellano se puede usar la palabra etiqueta, pero su función no es exactamente la misma que en blogs u otros sistemas de clasificación. Se emplean particularmente en Twitter y servicios similares para distinguir las etiquetas del resto del mensaje. Las etiquetas introducidas pueden rastrearse mediante los buscadores integrados distinguiéndolas claramente del resto de palabras, por lo que facilita la clasificación de los mensajes en estos servicios. Por su funcionamiento (no admite espacios) si las etiquetas están compuestas por varias palabras se deben escribir juntas, aunque es habitual que se distingan usando mayúsculas en la inicial de cada palabra para distinguir su significado. El uso de mayúsculas es técnicamente irrelevante porque el sistema no las discrimina, pero facilita la lectura. 
último caso se presenta una navegación específica y sonidos ambientales diversos, además de animaciones que incluyen un cursor desplazándose sobre las estrofas.

En esta panorámica, debemos llegar finalmente a la escritura poética de las redes sociales. Consideramos especialmente significativa la tuitpoesía, por su fuerte peso en el marco de la tuiteratura (Escandell 2014b: 41-42). La tuitpoesía, como podía preverse, se sitúa en una línea de tradición de brevedad que lo sitúa en la esfera del haikú desde una perspectiva estrictamente técnica. Se trata de textos que caben en el espacio de un tuit (140 caracteres originalmente y 280 desde hace relativamente poco tiempo), tanto en forma de prosas poéticas, o bien muchas recurriendo a la barra para separar varios versos, como en el caso de @MicroPoesia: "la lengua de la tarde / los labios de la noche / el ardor de la madrugada / el sosiego de la mañana", como consecuencia de que no siempre ha sido posible introducir saltos de línea en todas las representaciones visuales de esta red social debido a su pluralidad de clientes.

La búsqueda de lo estéticamente poético tiene, sin embargo, espacio en Twitter para el lugar común, cuando no abiertamente por la cita no atribuida, quién sabe si por falta de espacio, por considerarla sobradamente popular o por apropiación directa. Basta realizar una búsqueda de textos tan manoseados como "Si lloras por haber perdido el Sol, las lágrimas te impedirán ver las estrellas" para darnos cuenta de que hay miles de resultados (muchas veces sin ningún tipo de atribución al autor original).

Con todo, aunque la poesía en Twitter se sustenta principalmente en el uso de la red para difusión de micropoemas con menos intensidad que en el terreno de la micronarrativa, se puede rastrear el uso del hashtag \#tuitpoesía en múltiples usuarios, tanto con intención poética como simplemente satírica o humorística. En este sentido, su creación se presenta más diseminada y no siempre vinculada directamente con los criterios ramonianos y de búsqueda del ingenio de la tuitnarrativa: “\#tuitpoesía No son nuestros cuerpos, son nuestras almas las que nunca se separan, son ellas las que se anhelan, una y otra y otra vez". 


\section{Escritura no creativa: preámbulo a la tuiteratura no creativa}

Las escrituras conceptuales recogen el conjunto de prácticas de la apropiación experimental de textos situándose, como resulta evidente, en una esfera próxima a la del arte conceptual. Una de las contribuciones más importantes al estudio de este fenómeno ha sido realizada por Kenneth Goldsmith, quien hizo especial énfasis en la no originalidad, Ilevándole así a acuñar la etiqueta de uncreative writing (2011).

Más allá de desplazar la creatividad desde el resultado (la obra literaria) hacia la idea, proceso o técnica, siguiendo la estela del arte conceptual, la idea fundamental es la de la apropiación y resemantización textual, elementos que se sitúan por completo en la esfera del seminoauta bourriaudiano.

Señalaba Goldsmith que la web había permitido construir nuevas formas literarias herederas de la obra de Queneau gracias a la mediación tecnológica: "As a result, writers are exploring ways of writing that have been thought, traditionally, to be outside the scope of literary practice: word processing, databasing, recycling, appropriation, intentional plagiarism, identity ciphering, and intensive programming, to name but a few" (2011). ${ }^{8}$

El planteamiento de la apropiación es el que nos lleva directamente a las prácticas del remezclador y resemantizador absoluto que es el semionauta enunciado por Bourriaud a principios de siglo y cómo la reutilización de textos es, en sí mismo, un acto creativo:

Every work is issued from a script that the artist projects onto culture, considered the framework of a narrative that in turn projects new possible scripts, endlessly. The DJ activates the history of music by copying and pasting together loops of sound, placing recorded products in relation with each other. Artists actively inhabit cultural and social forms. The Internet user may create his or her own

8 "Como resultado, los escritores están explorando formas de escritura que han sido entendidas, tradicionalmente, como ajenas al alcance de la práctica literaria: procesamiento de textos, uso de bases de datos, reciclaje, apropiación, plagio intencionado, ocultación de la identidad y programación intensiva, por nombrar algunos ejemplos" (traducción propia). 
site or homepage and constantly reshuffle the information obtained, inventing paths that can be bookmarked and reproduced at will (Bourriaud 2005: 18). ${ }^{9}$

A partir de la idea de la remezcla de los textos y materiales ya existentes, disponibles para ser reutilizados porque el procomún de la red así lo permite (Ortega y Rodríguez 2011), debemos aceptar que estas estrategias creativas sitúan a los autores en una esfera de conceptualización. Como pronostica Goldsmith, "while the authors won't die, we might begin to view authorship in a more conceptual way: perhaps the best authors of the future will be ones who can write the best programs with which to manipulate, parse and distribute language-based practices" (2011). ${ }^{10}$

De tal manera, crear los sistemas para localizar las palabras de otros y facilitar su reutilización forman una nueva visión escritural y por ello la web social o 2.0, con redes como Twitter a la cabeza, suponen un caldo de cultivo fundamental. Ya hemos visto cómo en esta red social se publican fragmentos de otros, se escribe toda suerte de tuitpoesía, y, en líneas generales, se publican cantidades ingentes de textos categorizables gracias a estrategias como el etiquetado con hashtags. Esta extracción sería, en cierto modo, una escritura del software situada ya en la era de la plena posconceptualización. Según han señalado investigaciones precedentes, el presente sería "un segundo momento posconceptual que, a pesar de mantener ciertas similitudes en sus estrategias y técnicas creativas con la etapa de los 60 y 70, despliega un proyecto fundamentalmente crítico tanto hacia el propio arte conceptual como hacia su presente artístico, político y sociocultural" (Sánchez 2016: 93).

9 "Cada obra se gesta a partir de un guion que el artista proyecta sobre la cultura, considerando el marco de una narrativa que a su vez proyecta nuevos guiones posibles, hasta el infinito. El DJ activa la historia de la música mediante el copiado y pegado de bucles de sonido, colocando productos grabados en relación con los otros. Los artistas habitan activamente en formas culturales y sociales. Los usuarios de internet pueden crear su propio sitio o página web y reorganizar constantemente la información obtenida, inventando nuevas rutas que pueden ser guardadas y reproducidas a voluntad" (traducción propia).

10 "Aunque los autores no van a morir, quizá empecemos a ver la autoría de una forma más conceptual: quizá los mejores autores del futuro serán los que puedan escribir los mejores programas con los que manipular, analizar y distribuir acciones basadas en el lenguaje" (traducción propia). 
Esta revolución sociocultural es la base del rizoma 2.0 y de la ejecución del procomún, de compartir los bienes (digitales, intelectuales, inmateriales) en la red masivamente. En esta sopa de información, textos, imágenes, vídeos y todo tipo de materiales accesibles por todo el mundo, la autoría se debilita y desvanece. La autoridad y la propiedad se superan, pues son conceptos que pueden percibirse como egoístas e irrelevantes:

To think that what I consider to be "mine" was "original" would be blindingly egotistical. Sometimes I'll think that I've had an original thought or feeling and then, at 2 A.M., while watching an old movie on TV that I hadn't seen in many years, the protagonist will spout something that I had previously claimed as my own. In other words, I took his words (which, of course, weren't really "his words" at all), internalized them, and made them my own. This happens all the time (Goldsmith 2011).11

\section{POETuitéame: \\ acercamiento a la tuiteratura conceptual no creativa}

Con estos antecedentes llegamos finalmente a la propuesta de las autoras mexicanas Karen Villeda y Denise Audirac, POETuitéame (2014). El proyecto poético ha sido lo suficientemente destacado como para ser incluido en el tercer volumen de la antología de la Electronic Literature Collection (ELC3), una importante iniciativa de preservación del patrimonio textual digital que promueve el Massachusetts Institute of Technology.

Esta obra se situaría en una esfera de maduración dentro de las edades de la ciberescritura que investigadores como Flores (2017) han situado ya en una tercera generación de la poesía electrónica. Flores considera que esta tercera generación es el resultado de una época de maduración que llega tras la superación de los límites formales y de formato, como la obsolescencia de ciertas tecnologías (por ejemplo, Flash o Shockwave) en la ciberpoesía que hemos visto en las páginas precedentes y se fundamenta

11 “Creer que lo que considero 'mío' era 'original' sería ciegamente egoísta. A veces me parece que he tenido una idea o sensación original y luego, a las dos de la mañana, mientras veo una película vieja en la televisión que hacía años que no veía, el protagonista suelta algo que yo había pensado que era mío. Es decir, tomé sus palabras (que, por supuesto, no eran realmente 'sus palabras'), las había internalizado, y las había hecho mías. Esto pasa todo el tiempo" (traducción propia). 
en tecnologías estandarizadas (como HTML5), redes sociales, móviles y servicios (como, por ejemplo, Wikipedia).

La descripción que ofrece la ELC3 de POETuitéame respalda estos planteamientos y confirma la inclusión dentro de ese tercer cajón de la taxonomía generacional propuesta por Flores: "POETuitéame is built upon the public's misconceptions of poets and writing poetry. This collaborative online performance recreates a stereotyped poetic statement in 140 characters or less from hashtags related to 'reggaeton', 'poetry', 'pain', and 'suffering'. It is the first installation of its type in Mexico and perhaps in Latin America". ${ }^{12}$

La propuesta de una escritura descentralizada del poema representa una propuesta creativa diametralmente opuesta en el espacio de la digitalidad a la tendencia de la creación mediante software informático (Escandell 2014a: 2) (y, si éste es lo suficientemente avanzado, por las conocidas como inteligencias artificiales). Si en los casos de IA se ha hablado de las creatividades computacionales (López 2016), una propuesta centrada en la recuperación de textos de terceros es la transformación 2.0 de la fenomenología de la escritura desestructurada y potencialmente descentralizada del collage, o de la combinatoria de textos oulipiana.

Esto, siguiendo los preceptos de Goldsmith, no resta valor a la obra en cuanto a ejecución autoral, pues "mimesis and replication doesn't eradicate authorship" (2011). ${ }^{13}$ Evidentemente, la teoría de la semionáutica tampoco considera punible este hecho, pues se basa por completo en remezclar lo preexistente. En el caso de POETuitéame, sin embargo, debemos añadir un elemento adicional: los autores nominales de la web-herramienta son facilitadores, pero el acto semionáutico de ejecutar la escritura no creativa a partir de los tuits que localiza el sistema es el realizado por el receptor, que se convierte en escrilector pleno de la obra que genera para él en ese momento la web.

12 "POETuitéame se construye sobre las ideas equivocadas del público sobre los poetas y la escritura poética. Esta acción colaborativa en línea recrea una declaración poética estereotipada en 140 caracteres o menos a partir de etiquetas relacionadas con 'reguetón', 'poesía', 'dolor', y 'sufrimiento'. Es la primera instalación de este tipo en México y quizás en América Latina" (traducción propia).

13 "Mímesis y replicación no erradican la autoría" (traducción propia). 
En ese sentido, podríamos situar a POETuitéame en una órbita próxima al PAC de Eugenio Tisselli, en la medida en que el autor literario es un facilitador-programador, aquel que ha creado el marco que hace posible la ejecución por el receptor a partir de la materia prima que se suministra a la máquina. Dicho de otra manera, son plenamente autores conceptuales $y$, como tales, son autores plenos.

Emplear la red social Twitter no puede ser casual. A hechos prácticos como el dinamismo que supone la conversación en red tuitera, que no se detiene jamás, con sus miles de mensajes publicados en cada momento en multitud de idiomas por millones de usuarios distribuidos por todo el planeta, hay que usar las opciones de clasificación y categorización de la plataforma. Estamos hablando del hashtag como taxonomizador de la dinámica conversación en marcha de la red social.

Por el carácter breve y la tendencia al ingenio que muestran muchas de las expresiones literarias de este tipo, no debe extrañarnos que una buena parte de la producción creativa en Twitter gire en torno a géneros establecidos que han buscado siempre esos mismos ideales, como los acertijos, los aforismos, los albures, los calambures, lemas, consignas y proclamas, epigramas, greguerías, etc. En muchos de estos casos son construcciones autónomas, a veces compiladas en la propia red por determinados usuarios, que pueden ser el resultado también de la búsqueda del ingenio a raíz de la popularización de un hashtag para destacar entre la multitud. También es recurrente que un escritor emplee un hashtag concreto para aglutinar una serie de tuits. Es más: el hashtag puede asumir funciones paratextuales en las que se ofrece la clave descodificadora del mensaje principal, dando un giro adicional a lo escrito o ayudando a la correcta interpretación del mismo aportando un anclaje referencial que incorpora contexto, como en este ejemplo de la poeta Zilniya (@microversos): "Si no tengo sodio, ¿no tengo $\mathrm{Na}$ ? \#dudacontablaperiodica".

POETuitéame permite al receptor escoger entre hashtags vinculados con la poesía, lo que implica un primer filtrado: extrae los mensajes recientes publicados en Twitter que han usado esas etiquetas y, por tanto, hay una vocación claramente poética en ellos. También conlleva la extracción de los mensajes recientes de usuarios que contengan alguna de esas palabras en su nick, como por ejemplo "poeta". Es decir, aunque hay un 
marcado nivel de aleatoriedad, se hace a partir de un primer filtrado muy básico que permite una cierta intencionalidad literaria en los mensajes presentados ante el usuario.

Una vez el sistema ha recuperado tuits con uno o más hashtags, el usuario puede mover esos mensajes en la pantalla para reordenarlos y dar lugar así a la secuencia textual, que será completamente específica e irrepetible. Al hecho de que la extracción de tuits será diferente en cada ocasión hay que añadir el resultado de la interacción del receptor sobre los mensajes presentados en pantalla. Cada acción es, por tanto, irrepetible, pero también difícilmente preservable si no hay una intención previa de realizar capturas de pantalla. En este sentido, los textos generados son efímeros y destinados a regresar al miasma de voces que es Twitter.

\section{POETuitéame para el receptor. El papel activo del lector ante la interacción no creativa de la pieza}

La posición del lector es fundamental para comprender la obra, pues ésta es sólo tal cuando se ejecuta a raíz de la intervención directa de un receptor y a continuación presentamos unas observaciones fundamentales para comprender la obra y su impacto. ${ }^{14}$ En POETuitéame nos encontramos una vinculación expresa entre la idea de poesía y el reguetón como género musical. Esto se hace poniendo ante el lector hashtags con una dicotomía clave: la contraposición entre \#poesía (o las variantes \#poema y \#poeta) y \# reggaeton. Ambos términos son mediados por \#dolor y \#sufrir, por lo que la interfaz queda condicionada por estos términos en particular.

El lector-usuario es capaz de intuir, sin explicaciones adicionales, que la interfaz de la obra permite pinchar y arrastrar esas etiquetas hasta la

14 Nos parece de especial relevancia introducir este apartado en el presente texto dado que la obra no es ejecutable en estos momentos. Cuando en 2016 Twitter introduce una serie de modificaciones internas que afectan a qué funciones pueden realizarse por solicitudes externas, se mutila la capacidad de POETuitéame de actuar sobre los mensajes de la red. Esto afecta incluso a la copia para preservación digital que se realiza para la Electronic Literature Collection en su tercer volumen. Para reconstruir la experiencia receptora hemos empleado nuestras notas, observaciones y capturas de pantalla, tomadas durante los años en los que la obra funcionaba con normalidad. 
zona central de la pantalla. Al ejecutar esa acción, se activaba la búsqueda y extracción de tuits a partir de los mensajes recientes publicados en la red social. Esto permitía unir conceptos como los ofrecidos de forma predeterminada o cualquiera otra variante por esta combinatoria (figura 1).

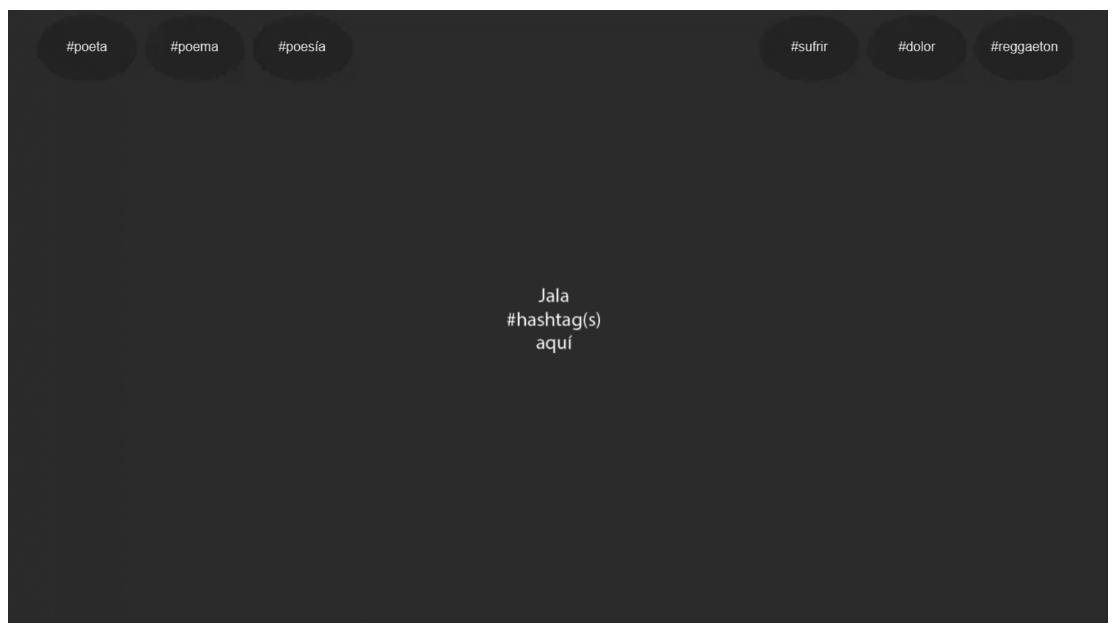

Figura 1. Interfaz de POETuitéame. Fuente: captura de pantalla propia (2016)

En pantalla se renderizaba una suerte de diagrama de relaciones: de la etiqueta o etiquetas centrales surgían los tuits más recientes que empleaban esas palabras. POETuitéame fotografiaba en cierto modo un momento concreto de Twitter a partir de las búsquedas de sus usuarios. El lector se situaba en la posición de ejecutor de su propia experiencia lectora al poder también actuar sobre la disposición en pantalla (figura 2).

Desde este punto de vista, y según los planteamientos de escritura nocreativa antes presentados, la obra ejecutaba un doble nivel de no-creatividad. En su estructura básica es el software el que generaba el ramo de tuit; en el nivel superior, es el receptor quien intervenía sobre los textos extraídos de la red. Su recolocación alteraba la secuencia lectora.

Cada acto del lector-usuario sobre la obra generaba un texto nuevo y único. Así, la experiencia propia es no replicable y el texto es la ejecución misma, que se regenera al cerrar la web. Explotar el corpus de Twitter permite una combinatoria virtualmente ilimitada por el enorme volumen de mensajes alojados en la red, nutriéndose de tal modo de todo el ruido de la 
conversación en marcha que es Twitter y darle forma artística sacando de ese contexto original gracias a la conceptualización de las autoras.

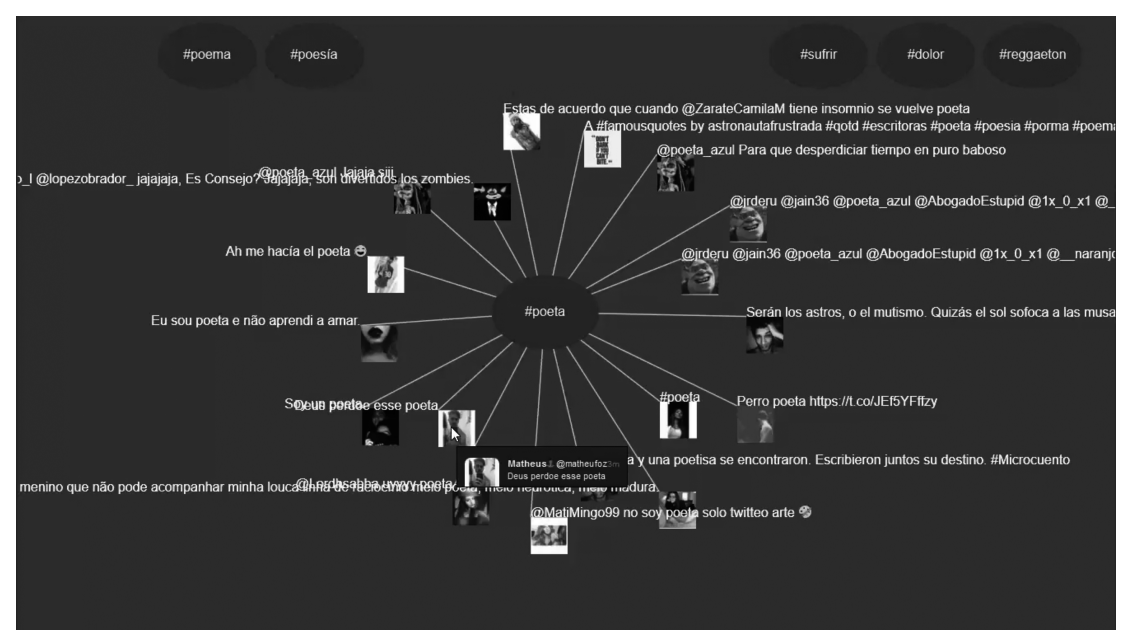

Figura 2. Resultado tras la búsqueda del hashtag \#poesía. Fuente: ELC, vol. 3 (2016)

\section{Conclusiones}

POETuitéame es una creación digital coherente con la trayectoria creativa de Karen Villeda que se hizo posible mediante la colaboración con Denise Audirac. La línea de Villeda desde sus comienzos la ha llevado por derroteros arriesgados y un claro interés desde sus primeros poemarios por trasladarlos hacia la esfera digital desde el papel.

En consecuencia, luego de los primeros poemarios impresos, un acto poético sobre la conversación en línea como el que representa Twitter (en tanto ejecución conceptual de intervención sobre los textos ajenos y, por tanto, permitiendo al usuario una escritura no-creativa), puede verse como un paso lógico y coherente dentro de la maduración de la autora. Esta experimentación refuerza sus intereses, supone un interesante salto técnico en cuanto a complejidad con respecto a obras basadas en recursos como el stop-motion y evidencia que la colaboración con Audirac no es superficial. 
En definitiva, la poesía de Karen Villeda y Denise Audirac en POETuitéame se enmarca en la trayectoria teórica propuesta por Kenneth Goldsmith como conceptual y no-creativa. Igualmente, parte de los ideales de remezcla y reutilización semionáutica de Nicolas Bourriaud. Para ello, los textos resultantes y la opción de manipulación que se ofrece al lector-usuario se genera tomando como punto de partida el mar de mensajes de Twitter, escritos por terceros. Esas son las aguas donde las autoras nos han propuesto pescar tuits usando como cebo una serie de hashtags. Con el material recuperado, es el receptor quien decide cómo gestionar el material recibido.

Las autoras lo son en la medida en que definen, programan y facilitan al receptor la ejecución de la obra. Esto da lugar a una autoría con diferentes niveles: en la base se encuentra el flujo de textos de Twitter y en la cima el lectoautor que actúa sobre la materia prima. En una posición intermedia fundamental están las autoras, como facilitadoras y ejecutoras de las herramientas que permiten a unos actuar sobre los otros. Esta mediación es la de la autoría en la no-creatividad y es resultado directo de una visión conceptual del acto poético.

POETuitéame trasciende, como sugieren las implicaciones antes realizadas, la autoría clásica para llegar al autor como responsable de un código y de la gestación de herramientas, situándolo en esa posición de intermediación que hemos referido ya. Villeda y Audirac son conceptualizadoras que han diseñado la obra, pero no sus ejecutoras ni las autoras de los materiales que funcionan como input.

Asimismo, la obra resulta efímera por su propia naturaleza, más allá de que los cambios técnicos en Twitter hicieran que ya no sea operativa. Mientras funcionaba, la rápida generación de contenidos por los millones de usuarios de la red social Twitter hacía ya que cada uso fuera diferente: no había dos ejecuciones iguales y era virtualmente imposible reproducir acciones con idéntico resultado. Por tanto, cada lectoautor, como usuario y receptor, tenía una experiencia única. Por otro lado, su propia dependencia de las capacidades y permisos que una red social, propiedad de una empresa privada, diera a terceros, suponía que, ante cualquier modificación técnica o restricción de autorizaciones, no pudiera ejecutarse más, como finalmente sucedió. La escritura digital es volátil, sin duda, por la confluencia de factores técnicos que dependen de terceros y que no están 
al alcance de sus creadores, y este cambio ha afectado a POETuitéame. Sin embargo, como obra conceptual, es tan importante la idea de la ejecución como el resultado, y si bien la ejecución ya no es posible, tanto la idea como su código siguen existiendo y son testimonio de la obra propuesta por Villeda y ejecutada junto a Audirac.

En su voluntad exploradora y experimentadora, Villeda trasladó sus inquietudes, que ya habíamos visto en poesía impresa y videopoesía, a una intervención sobre redes sociales. Una obra dependiente por completo para su ejecución de un colectivo, una empresa privada y unos finos hilos de código informático que lo unían todo y sobre los que decidió intervenir y actuar. Esto es algo, por otro lado, frecuente en la poesía digital en sí misma. Es todavía hoy un extenso campo exploratorio lleno de posibilidades. Autoras como Villeda emplean, con la misma naturalidad que el verso sobre la hoja impresa, la tecnología y el código informático para ejecutar ideas que retan al lector a explorar los límites de lo poético. Si bien esto sugiere que la poesía digital todavía no ha alcanzado una madurez y que está en fase de aceleración, los estímulos para la creatividad que abre y las ejecuciones que se realizan son de gran interés para el público que, quizá versado en la poesía, o quizá más inclinado hacia lo estrictamente tecnológico, puede sentirse atraído por la esfera intermedia de estas obras.

\section{Bibliografía}

Aguilar, Andrea. "La poesía estalla en las redes", en El País (25 de julio de 2014). Artículo en línea disponible en: <https://elpais.com/cultura/2014/07/21/babelia/1405960941_843796.html> [consultado el 20 de julio de 2018].

BAETENS, JAN. "Poesía electrónica: entra la imagen y la performance. Un análisis cultural", en Escrituras digitales. Tecnologías de la creación de la era virtual. Edición de Virgilio Tortosa. Alicante: Servicio de Publicaciones Universidad de Alicante, 2008. 243-266.

Bourriaud, Nicolas. Postproduction. Culture as screenplay: How art reprograms the world [2002]. Nueva York: Lukas \& Sterling, 2005.

Castaño, Yolanda. "Transpoética", en Perfopoesía. Sobre la poesía escénica y sus redes. Yolanda Castaño et al. (coord.). Sevilla: Cangrejo Pistolero Ediciones, 2011. 21-28.

Cross, ElSA. "Karen Villeda. Nuevas formas expresivas", en Revista de la Universidad de México, 99 (2012): 90-92. 
DACHS, RAMON. Intermínims de navegació poética (1996). Obra en línea disponible en: <http://www.hermeneia.net/interminims/> [consultado el 20 de julio de 2018].

Enciclopedia de la literatura en México. 'Karen Villeda' (2011). Enciclopedia en línea disponible en: <http://www.elem.mx/autor/datos/2021> [consultado el 20 de julio de 2018].

Escandell Montiel, Daniel. "Programando ficciones. La máquina que quiso ser Ken Follet", en El Cuaderno. Oviedo, 54 (2014a): 2-4.

EsCandell Montiel, Daniel. "Tuiteratura: la frontera de la microliteratura en el espacio digital", en Iberic@l. Revue d'études ibériques et ibéro-américaines. París, 5 (2014b): 37-48.

ESCANDEll MONTIEL, DANIEl. "Logoemesis y cultura textovisual: figuras de la generación y visibilización del texto en el arte escrito mediado por las pantallas", en Tropelías. Revista de Teoría de la Literatura y Literatura Comparada. Zaragoza, 27 (2017): 56-66.

EzZAT, Sharif. Like Stars in a Clear Night Sky (2006). Obra disponible en línea en: $<$ http://sharifezzat.com/stars/> [consultado el 20 de julio de 2018].

FloRES, LeONARDO. "La literatura electrónica latinoamericana, caribeña y global: generaciones, fases y tradiciones", en Artelogie. París, 11 (2017). Artículo disponible en línea en: <https://journals.openedition.org/artelogie/1590> [consultado el 20 de julio de 2018].

Funkhouser, Chris. Prehistoric Digital Poetry. An Archaeology of Forms, 19591995. Tuscaloosa: University of Alabama Press, 2007.

Goldsmith, Kenneth. Uncreative Writing. Nueva York: Columbia University Press, 2011.

LEWIS, JASON EDWARD. Speak (2010). Obra en línea disponible en: <http://itunes. apple.com/es/app/speak/id406078727? mt=8> [consultado el 20 de julio de 2018].

LEWIS, JasOn EDWARD. Know (2011). Obra en línea disponible en: <http://itunes. apple.com/es/app/know/id446777294?mt=8> [consultado el 20 de julio de 2018].

LóPEZ de MÁNTARAS, RAmÓN. "La inteligencia artificial y las artes. Hacia una creatividad computacional", en vVAA. El próximo paso. La vida exponencial. Madrid: BBVA, 2016. 99-123.

Martín Centeno, Óscar. "Poética multimedia", en Yolanda Castaño et al. (coord.). Perfopoesía. Sobre la poesía escénica y sus redes. Sevilla: Cangrejo Pistolero Ediciones, 2011. 29-40.

Montoto, Nacho. "Perfopoesía: red de redes", en Yolanda Castaño et al. (coord.). Perfopoesía. Sobre la poesía escénica y sus redes. Sevilla: Cangrejo Pistolero Ediciones, 2011. 41-46.

MORA, Vicente LUIS. El lectoespectador. Barcelona: Seix Barral, 2012.

Ortega, F. y JoAquín RodríGuez. El potlatch digital. Wikipedia y el triunfo del procomún y el conocimiento compartido. Madrid: Cátedra, 2011.

Ortiz, Santiago. Bacterias argentinas (2004). Obra en línea disponible en: <http:// moebio.com/santiago/bacterias/> [consultado el 20 de julio de 2018]. 
Remírez, Félıx. "Poetuitéame", en Biblumliteraria. Disponible en: <http://biblumliteraria.blogspot.com/2017/02/poetuiteame.html> [consultado el 20 de julio de 2018].

SÁnCHEZ ApAricio, VeGA. "Las escrituras alegóricas del software: colapso estético, rearticulación ética, desde el espacio mexicano", en Caracteres. Estudios culturales y críticos de la esfera digital. Salamanca, 5-2 (2016): 80-113.

SChiavetta, Bernardo. Raphèl (2001). Obra en línea disponible en: <http://www. raphel.net/> [consultado el 20 de julio de 2018].

Tisselli, Eugenio. PAC - Poesía Asistida por Computadora (2006). Obra en línea disponible en: <http://www.motorhueso.net/pac/> [consultado el 20 de julio de 2018].

Uribe, Ana María. Tipoemas y Anipoemas (2003). Obra en línea disponible en: $<$ http://amuribe.tripod.com> [consultado el 20 de julio de 2018].

Villeda, Karen y Denise Audirac. POETuitéame (2014). Obra en línea disponible en: <http://www.poetronica.net/poetuiteame.html> [consultado el 20 de julio de 2018].

DANIEL ESCANDELL MONTIEL

Doctor en Filología Hispánica por la Universidad de Salamanca (2012), con premio extraordinario de doctorado. Es director de la revista Caracteres. Estudios culturales y críticos de la esfera digital y miembro de diversos grupos y redes de investigación como el IEMYRhd (Instituto de Estudios Medievales, Renacentistas y Humanidades Digitales) o ILICIA (Inscripciones literarias en la ciencia).

Ha publicado artículos en revistas como Ínsula, Inti o El profesional de la información. Es autor de libros como Escrituras para el siglo XXI. Literatura y blogosfera (2014), Mi avatar no me comprende. Cartografías de la suplantación y el simulacro (2016) y No es web para críticas. El crítico cultural ante los medios digitales y la búsqueda de su espacio en la red (2018). Es coautor, junto a Fernando R. de la Flor, de El gabinete de Fausto. "Teatros" de la escritura y la lectura a un lado y otro de la esfera digital (2014). 
Tiene en marcha, como co-investigador principal, los proyectos "New Approaches to Transmedia and Language Pedagogy" y "Transmedia Practices in Higher Education: OERs for students by students", financiados por el Reino Unido, y "Lectoescritura digital", financiado por el Ministerio de Educación, Política Social y Deporte (España).

Actualmente es lecturer de Spanish \& Latin American Studies en la Manchester Metropolitan University. Ha sido docente en instituciones como la Universidad de Salamanca, la Universidad de Valladolid, la Universidad Internacional Menéndez Pelayo, la James Madison University, etc., y ha sido profesor colaborador en otros programas de doctorado y máster en instituciones internacionales como experto en literatura española e hispanoamericana y humanidades digitales. 